\title{
Ureter Obstruction
}

National Cancer Institute

\section{Source}

National Cancer Institute. Ureter Obstruction. NCI Thesaurus. Code C79802.

Blockage of the normal flow of urine in the ureter. 